\title{
Utilizing Pulmonary Function Parameters to Predict Dysphagia in Individuals With Cervical Spinal Cord Injuries
}

\author{
So Jung Lee, MD, Sungchul Huh, MD, Sung-Hwa Ko, MD, Ji Hong Min, MD, Hyun-Yoon Ko, MD, PhD
}

Department of Rehabilitation Medicine, Pusan National University Yangsan Hospital, Pusan National University School of Medicine, Yangsan, Korea

Objective To utilize pulmonary function parameters as predictive factors for dysphagia in individuals with cervical spinal cord injuries (CSCIs).

Methods Medical records of 78 individuals with CSCIs were retrospectively reviewed. The pulmonary function was evaluated using spirometry and peak flow meter, whereas the swallowing function was assessed using a videofluoroscopic swallowing study. Participants were divided into the non-penetration-aspiration group (score 1 on the Penetration-Aspiration Scale [PAS]) and penetration-aspiration group (scores 2-8 on the PAS). Individuals with pharyngeal residue grade scores $>1$ were included in the pharyngeal residue group.

Results The mean age was significantly higher in the penetration-aspiration and pharyngeal residue groups. In this study, individuals with clinical features, such as advanced age, history of tracheostomy, anterior surgical approach, and higher neurological level of injury, had significantly more penetration-aspiration or pharyngeal residue. Individuals in the penetration-aspiration group had significantly lower peak cough flow (PCF) levels. Individuals in the pharyngeal residue group had a significantly lower forced expiratory volume in 1 second (FEV1). According to the receiver operating characteristic curve analysis of PCF and FEV1 on the PAS, the cutoff value was $140 \mathrm{~L} / \mathrm{min}$ and $37.5 \%$ of the predicted value, respectively.

Conclusion Low PCF and FEV1 values may predict the risk of dysphagia in individuals with CSCIs. In these individuals, active evaluation of swallowing is recommended to confirm dysphagia.

Keywords Cervical cord, Spinal cord injuries, Deglutition disorders, Respiratory function tests

Received October 4, 2021; Revised November 9, 2021; Accepted November 15, 2021; Published online December 31, 2021

Corresponding author: Hyun-Yoon Ko

Department of Rehabilitation Medicine, Pusan National University Yangsan Hospital, Pusan National University School of Medicine, 20 Geumo-ro, Mulgeum, Yangsan 50612, Korea. Tel: +82-55-360-4000, Fax: +82-55-360-4251, E-mail: drkohy@gmail.com

ORCID: So Jung Lee (https://orcid.org/0000-0002-2282-4030); Sungchul Huh (https://orcid.org/0000-0002-7740-8050); Sung-Hwa Ko (https://orcid. org/0000-0003-4900-5972); Ji Hong Min (https://orcid.org/0000-0002-2097-9194); Hyun-Yoon Ko (https://orcid.org/0000-0001-5506-7219).

(c) This is an open-access article distributed under the terms of the Creative Commons Attribution Non-Commercial License (http://creativecommons.org/ licenses/by-nc/4.0) which permits unrestricted noncommercial use, distribution, and reproduction in any medium, provided the original work is properly cited. Copyright $\odot 2021$ by Korean Academy of Rehabilitation Medicine 


\section{INTRODUCTION}

Dysphagia is a relatively common complication among individuals with acute cervical spinal cord injuries (CSCIs). According to several previous studies, the incidence of dysphagia in individuals with CSCI varies from $16 \%$ to 80\% [1-4]. Dysphagia after CSCI can increase the risk of aspiration pneumonia, leading to increased morbidity and mortality [5-8]. Therefore, early detection of dysphagia is essential for adequate nutrition and prevention of aspiration pneumonia. Several previous studies have identified risk factors for dysphagia in individuals with CSCI, such as age, tracheostomy, severe paralysis, voice quality, and anterior cervical surgery $[9,10]$. In addition, inefficient clearance of residue in the vallecula and pyriform sinuses can lead to an increased risk of postswallow aspiration and subsequent pulmonary infection [11].

Respiratory dysfunction is a leading cause of morbidity and mortality in individuals with CSCI $[12,13]$. Furthermore, respiratory dysfunction in spinal cord injury has a multifactorial pathophysiology and results from weakness of the diaphragm and accessory muscle, reduced cough function and surfactant production, and unopposed vagal tone, leading to increased bronchospasm and secretions [6]. Following acute spinal cord injury, the neurological level of injury and the completeness of injury related to the phrenic nucleus at the C3-C5 segments are the most important determinants of respiratory failure. Swallowing and respiratory systems share the aerodigestive tract as a common anatomical area. In healthy individuals, swallowing occurs during the expiratory phase of breathing. Swallowing apnea is an involuntary pause in breathing during swallowing. This prevents laryngeal penetration and tracheal aspiration [14-17]. However, it can be difficult for individuals with CSCI and diaphragmatic dysfunction to hold their breath while swallowing.

Several previous studies have shown that respiratory function assessment is useful for predicting impairment in the swallowing function among individuals with ischemic stroke $[18,19]$. However, to the best of our knowledge, no study has reported that impaired pulmonary function parameters are physiologically related to reduced swallowing function in individuals with CSCI. The current study aimed to investigate whether pulmonary function parameters could be used to predict dysphagia in individuals with CSCI.

\section{MATERIALS AND METHODS}

\section{Participants}

Medical records of individuals with CSCI between 2014 and 2019 were retrospectively reviewed. The study procedures were reviewed and approved by the Pusan National University Yangsan Hospital Institutional Review Board for human participants (No. 05-2019-155). We certify that all applicable institutional and governmental regulations concerning the ethical use of human volunteers were followed during the course of this research. The inclusion criteria were: (1) individuals with CSCI diagnosed by a physician; (2) individuals hospitalized for CSCI treatment; and (3) individuals who underwent the swallowing function test using videofluoroscopic swallowing study (VFSS) and the pulmonary function test using spirometry and peak flow meter during their hospital stay. The exclusion criteria were: (1) individuals who were unable to undergo the swallowing or pulmonary function test; (2) individuals with a history of diseases that affect the swallowing function, such as stroke and neuromuscular diseases; and (3) individuals who had an interval of $>28$ days between the swallowing and pulmonary function tests. Finally, 78 individuals were enrolled based on the inclusion and exclusion criteria. However, the IRB waived the informed consent.

\section{Swallowing function assessment}

The swallowing function was confirmed by VFSS. It was performed by a well-trained physiatrist and an occupational therapist using a modified Logemann protocol [20]. The test diet included $2 \mathrm{~mL}, 5 \mathrm{~mL}$, and a cup of diluted barium, liquid with food thickener, soup, porridge, and rice. It was conducted in the upright sitting position, and lateral images were obtained using real-time fluoroscopy. The severity of laryngeal penetration or tracheal aspiration in VFSS was evaluated using the Penetration-Aspiration Scale (PAS). The PAS evaluates airway invasions and has a maximum score of 8 points. PAS is scored based on the depth to which material passes into the airway and whether material entering the airway can be expelled. A score of 1 reflects no entry of material into the airway, scores of 2-5 reflect laryngeal penetration of material, while scores of 6-8 reflect the tracheal aspiration of ma- 
terial below the true vocal folds [21]. We regarded individuals who scored 1 on the PAS as the non-penetrationaspiration (non-PA) group, and those who scored $\geq 2$ on the PAS on one or more swallows were considered as the penetration-aspiration (PA) group.

Additionally, the residual material in the vallecula or pyriform sinuses was assessed using pharyngeal residue grade (PRG) scores. The PRG has four-level scores ranging from 0 to 3 . PRG 0 indicates no residue in the vallecula or pyriform sinuses, regarded as the non-pharyngeal residue group in this study. PRG 1 refers to $<10 \%$, PRG 2 refers to $10 \%-50 \%$, and PRG 3 refers to $>50 \%$ filling of the vallecula or pyriform sinuses by the food substance [22]. We included individuals with more than PRG 1 score in the pharyngeal residue group.

\section{Pulmonary function assessment}

Pulmonary function test was performed in an upright position using a spirometer (Pony FX MIP/MEP; COSMED Inc., Rome, Italy). The tests were performed in three consecutive trials supported by experienced pulmonary therapists to make the results reliable, and a maximum value was used for analysis. Tidal volume, forced vital capacity, forced expiratory volume in $1 \mathrm{sec}-$ ond (FEV1), maximal inspiratory pressure, and maximal expiratory pressure were measured using spirometry. Peak cough flow (PCF) was used as a parameter to measure voluntary coughing ability using a peak flow meter (Mini Wright flow meter; Clement Clarke International Ltd., Essex, UK). PCF was defined as the highest point of the flow-volume curve obtained during coughing.

\section{Statistical analysis}

Statistical analysis was performed using SPSS software version 20.0 (IBM Corp., Armonk, NY, USA). The normality of the sample was confirmed with the Shapiro-Wilk test performed before Student t-test and Pearson correlation analyses. Categorical variables were assessed using the chi-squared test, whereas continuous variables were analyzed using Student t-test. The correlations of PAS and PRG scores with pulmonary function test parameters or PCF in all participants were analyzed using Pearson correlation analysis. A multivariate logistic regression analysis was conducted to address all variables. We investigated the receiver operating characteristic (ROC) curves for PCF and FEV1, which exhibited the strongest relationship with PAS and PRG and identified cutoff values, sensitivities, and specificities. The statistical significance of all analyses was set at $\mathrm{p}<0.05$.

\section{RESULTS}

\section{General characteristics and clinical features}

General demographics of the participants are presented in Table 1. Out of 78 individuals with CSCI, 69 were male. The mean age was $58.6 \pm 15.4$ years. Forty participants (51.28\%) had laryngeal penetration or tracheal aspiration, whereas $37(47.43 \%)$ had pharyngeal residue in VFSS. Among all participants, 37 (47.43\%) underwent tracheostomy, whereas 31 (39.74\%) underwent surgery using the anterior approach. There were $52(66.67 \%)$ and 26 (33.33\%) individuals in whom the neurological level of injury was at C1-C4 and C5-C8, respectively. Thirty-seven participants (47.43\%) had a complete injury, whereas $41(52.56 \%)$ had an incomplete injury.

\section{Correlation between pulmonary and swallowing} function parameters in $\mathrm{CSCI}$

All pulmonary function test and PCF parameters were

Table 1. General demographics of the participants

\begin{tabular}{|lc}
\hline \multicolumn{1}{|c}{ Characteristic } & \multicolumn{1}{c}{ Value } \\
\hline Age (yr) & $58.6 \pm 15.4$ \\
\hline Sex & $69(88.46)$ \\
\hline Male & $9(11.54)$ \\
\hline Female & \\
\hline Tracheostomy & $37(47.44)$ \\
\hline Positive & $41(52.56)$ \\
\hline Negative & $31(39.74)$ \\
\hline Surgery & $47(60.26)$ \\
\hline Anterior approach & \\
\hline Others & $52(66.67)$ \\
\hline Neurological level of injury & $26(33.33)$ \\
\hline Upper (C1-C4) & \\
\hline Lower (C5-C8) & $37(47.44)$ \\
\hline ASIA impairment scale & $41(52.56)$ \\
\hline A
\end{tabular}

Values are presented as mean \pm standard deviation or number (\%).

ASIA, American Spinal Injury Association. 
Table 2. Correlation between pulmonary function parameters and PAS or PRG in CSCI

\begin{tabular}{cccccc}
\hline \multirow{2}{*}{$\begin{array}{c}\text { Pulmonary function } \\
\text { parameters }\end{array}$} & \multicolumn{2}{c}{ PAS } & \multicolumn{2}{c}{ PRG } \\
\cline { 2 - 3 } \cline { 2 - 3 } TV & Correlation coefficients & p-value & & Correlation coefficients & p-value \\
\hline FVC & -0.243 & $0.032^{*}$ & & -0.275 & $0.015^{*}$ \\
FEV1 & -0.441 & $0.000^{*}$ & & -0.432 & $0.000^{*}$ \\
MIP & -0.470 & $0.000^{*}$ & -0.543 & $0.000^{*}$ \\
MEP & -0.394 & $0.000^{*}$ & -0.430 & $0.000^{*}$ \\
PCF & -0.363 & $0.001^{*}$ & & -0.294 & $0.009^{*}$ \\
\hline
\end{tabular}

PAS, Penetration-Aspiration Scale; PRG, pharyngeal residue grade; CSCI, cervical spinal cord injuries; TV, tidal volume; FVC, forced vital capacity; FEV1, forced expiratory volume in one second; MIP, maximal inspiratory pressure; MEP, maximal expiratory pressure; PCF, peak cough flow. ${ }^{*} \mathrm{p}<0.05$.

significantly negatively correlated with PAS. Among them, FEV1 and PCF showed the strongest correlation, with correlation coefficients of -0.470 and -0.488 , respectively. Similarly, all of the analyzed parameters were observed to show significant negative correlations with the PRG. Among them, the correlation coefficients of FEV1 and PCF were -0.543 and -0.484 , respectively, showing the strongest correlation (Table 2).

\section{Comparison between the PA and non-PA groups}

Table 2 shows the differences in participants' demographics, clinical features, and parameters of pulmonary function test and PCF between the PA and nonPA groups. While 40 participants $(51.28 \%)$ had laryngeal penetration or tracheal aspiration, $38(48.72 \%)$ had no laryngeal penetration or tracheal aspiration in the VFSS. The PA group had a significantly higher mean age than the non-PA group $(p=0.001)$. The proportion of the PA group was significantly higher in the patient group with a history of tracheostomy $(\mathrm{p}=0.001)$, underwent the anterior approach surgery $(\mathrm{p}=0.005)$, and with the $\mathrm{C} 1-\mathrm{C} 4$ American Spinal Injury Association (ASIA) level ( $\mathrm{p}=0.01)$.

Except for the tidal volume, PCF and all pulmonary function test parameters had significantly lower values in the PA group than those in the non-PA group. To determine independent risk factors for laryngeal penetration or tracheal aspiration, we placed the variables that were found to be significant in the univariate analysis (age, forced vital capacity, FEV1, maximal inspiratory pressure, maximal expiratory pressure, and PCF) into a multivariate logistic regression model. Multinomial logistic regression analysis revealed that the risk of penetration or as- piration significantly increased as the age increased and the PCF decreased ( $\mathrm{p}=0.002$ and $\mathrm{p}=0.017$, respectively). Furthermore, the risk of penetration or aspiration significantly increased in participants who underwent anterior surgery and those with a higher ASIA impairment scale (AIS) level ( $\mathrm{p}=0.000$ and $\mathrm{p}=0.012$, respectively) (Table 3 ).

\section{Comparison between the pharyngeal and non- pharyngeal residue groups}

Comparisons between groups with and without pharyngeal residue are presented in Table 3. In the VFSS, 37 participants $(47.44 \%)$ had pharyngeal residue, whereas 41 (52.56\%) did not. The mean age was significantly higher in the residue group $(\mathrm{p}=0.002)$. The proportion of the pharyngeal residue group was significantly higher in the patient group with a history of tracheostomy $(\mathrm{p}=0.001)$, underwent the anterior approach surgery $(\mathrm{p}=0.001)$, and with the C1-C4 AIS level ( $\mathrm{p}=0.01)$.

PCF and all pulmonary function test parameters, except for the tidal volume, had significantly lower values in the pharyngeal residue group (Table 3). To determine independent risk factors for pharyngeal residue, we placed the variables that were found to be significant in the univariate analysis (age, forced vital capacity, FEV1, maximal inspiratory pressure, maximal expiratory pressure, PCF, and tracheostomy) into a multivariate logistic regression model. Multinomial logistic regression analysis showed that the risk of pharyngeal residue significantly increased as the age increased and the FEV1 decreased $(p=0.002$ and $p=0.026$, respectively). In addition, the risk of penetration or aspiration significantly increased in participants who underwent anterior surgery and those with 
Table 3. Comparison between the penetration-aspiration and non-penetration-aspiration groups in terms of demographics, clinical features, and parameters of pulmonary function test and multivariate logistic regression analysis of penetration-aspiration risk factors

\begin{tabular}{|c|c|c|c|c|c|}
\hline \multirow{2}{*}{ Variable } & \multirow{2}{*}{$\begin{array}{l}\text { Penetration-aspiration } \\
\qquad(n=40)\end{array}$} & \multirow{2}{*}{$\begin{array}{l}\text { Non-penetration- aspiration } \\
\qquad(\mathrm{n}=\mathbf{3 8})\end{array}$} & \multirow{2}{*}{ p-value } & \multicolumn{2}{|c|}{ Multivariate analysis } \\
\hline & & & & $\beta$ coefficient & p-value \\
\hline Age (yr) & $64.03 \pm 11.08$ & $52.89 \pm 17.36$ & $0.001^{*}$ & 0.279 & $0.002^{*}$ \\
\hline Sex & & & 0.083 & - & \\
\hline Male & $38(95.0)$ & $31(81.6)$ & & & \\
\hline Female & $2(5.0)$ & $7(18.4)$ & & & \\
\hline Tracheostomy & & & $0.001^{*}$ & 0.085 & 0.392 \\
\hline Positive & $26(65.0)$ & $11(28.95)$ & & & \\
\hline Negative & $14(35.0)$ & $27(71.05)$ & & & \\
\hline Surgery & & & $0.005^{*}$ & 0.349 & $0.000^{*}$ \\
\hline Anterior approach & $22(55.0)$ & $9(23.68)$ & & & \\
\hline Others & $18(45.0)$ & $29(86.32)$ & & & \\
\hline Neurological level of injury & & & $0.01^{*}$ & 0.242 & $0.012^{*}$ \\
\hline Upper (C1-C4) & $32(80.0)$ & $20(52.63)$ & & & \\
\hline Lower (C5-C8) & $8(20.0)$ & $18(47.37)$ & & & \\
\hline ASIA impairment scale & & & 0.375 & - & \\
\hline A & $21(52.5)$ & $16(42.11)$ & & & \\
\hline $\mathrm{B}, \mathrm{C}$, or D & $19(47.5)$ & $22(57.89)$ & & & \\
\hline $\mathrm{TV}(\mathrm{L})$ & $0.43 \pm 0.16$ & $0.47 \pm 0.16$ & 0.248 & - & \\
\hline FVC (\%pred) & $40.63 \pm 22.85$ & $48.96 \pm 24.06$ & $0.004^{*}$ & 0.181 & 0.294 \\
\hline FEV1 (\%pred) & $39.42 \pm 28.59$ & $47.52 \pm 29.01$ & $0.000^{*}$ & -0.187 & 0.308 \\
\hline $\mathrm{MIP}\left(\mathrm{cmH}_{2} \mathrm{O}\right)$ & $25.73 \pm 19.88$ & $48.68 \pm 29.56$ & $0.000^{*}$ & 0.020 & 0.901 \\
\hline $\operatorname{MEP}\left(\mathrm{cmH}_{2} \mathrm{O}\right)$ & $20.28 \pm 17.82$ & $41.39 \pm 31.71$ & $0.001^{*}$ & -0.061 & 0.682 \\
\hline PCF (L/min) & $107.25 \pm 87.06$ & $215.79 \pm 123.39$ & $0.000^{*}$ & -0.398 & $0.017^{*}$ \\
\hline
\end{tabular}

Values are presented as mean \pm standard deviation or number (\%).

ASIA, American Spinal Injury Association; \%pred, percentage of predicted normal; TV, tidal volume; FVC, forced vital capacity; FEV1, forced expiratory volume in one second; MIP, maximal inspiratory pressure; MEP, maximal expiratory pressure; PCF, peak cough flow.

${ }^{*} \mathrm{p}<0.05$.

a higher AIS level ( $\mathrm{p}=0.000$ and $\mathrm{p}=0.016$, respectively) (Table 4).

\section{ROC analysis of PCF and FEV 1 in the presence of PA or} pharyngeal residue

This study showed that $140 \mathrm{~L} / \mathrm{min}$ as the cutoff value of PCF was an ideal diagnostic value with balanced sensitivity and specificity ( $65.8 \%$ and $70.0 \%$, respectively) and the highest area under the curve (AUC) of 0.755 (95\% confidence interval [CI], 0.649-0.860; $\mathrm{p}=0.000$ ) and $37.5 \%$ of the predicted value as the appropriate cutoff value of FEV1 with balanced sensitivity and specificity $(65.8 \%$ and $62.5 \%$, respectively) and the highest AUC of 0.744 (95\% CI, 0.636-0.852, p=0.000) in the presence of PA (Fig. 1).
However, we could not find appropriate cutoff values for PCF and FEVl in individuals with pharyngeal residue.

\section{DISCUSSION}

Dysphagia is a relatively common complication that occurs after acute CSCI. The consequences of dysphagia in CSCI include life-threatening complications, such as aspiration pneumonia, chemical pneumonitis, and airway obstruction. Dysphagia in CSCI can increase the length of hospital stay, delay the rehabilitation course, and affect the ultimate discharge [1]. Therefore, early evaluation and intervention for dysphagia are imperative to reduce morbidity and mortality in individuals with CSCI [5]. 
Table 4. Comparison between the pharyngeal and non-pharyngeal residue groups in terms of demographics, clinical features, injury, and parameters of pulmonary function test and multivariate logistic regression analysis of pharyngeal residue risk factors

\begin{tabular}{|c|c|c|c|c|c|}
\hline \multirow{2}{*}{ Variable } & \multirow{2}{*}{$\begin{array}{c}\text { Pharyngeal } \\
\text { residue group }(n=37)\end{array}$} & \multirow{2}{*}{$\begin{array}{l}\text { Non-pharyngeal } \\
\text { reside group }(n=41)\end{array}$} & \multirow{2}{*}{ p-value } & \multicolumn{2}{|c|}{ Multivariate analysis } \\
\hline & & & & $\beta$ coefficient & p-value \\
\hline Age (yr) & $64.24 \pm 13.16$ & $53.51 \pm 15.71$ & $0.002^{*}$ & 0.279 & $0.002^{*}$ \\
\hline Sex & & & 0.487 & - & \\
\hline Male & $34(94.89)$ & 35 (85.37) & & & \\
\hline Female & $3(8.11)$ & $6(14.63)$ & & & \\
\hline Tracheostomy & & & $0.001^{*}$ & 0.144 & 0.154 \\
\hline Positive & $25(67.57)$ & $12(29.27)$ & & & \\
\hline Negative & $12(32.43)$ & $29(70.73)$ & & & \\
\hline Surgery & & & $0.001^{*}$ & 0.403 & $0.000^{*}$ \\
\hline Anterior approach & $22(59.46)$ & $9(21.95)$ & & & \\
\hline Others & $15(40.54)$ & $32(78.05)$ & & & \\
\hline AIS level of injury & & & $0.01^{*}$ & 0.233 & $0.016^{*}$ \\
\hline Upper (C1-C4) & $30(81.08)$ & $22(53.66)$ & & & \\
\hline Lower (C5-C8) & 7 (18.92) & $19(46.34)$ & & & \\
\hline ASIA impairment scale & & & 0.173 & - & \\
\hline A & $21(56.76)$ & $16(39.02)$ & & & \\
\hline $\mathrm{B}, \mathrm{C}$, or D & $16(43.24)$ & $25(60.98)$ & & & \\
\hline $\mathrm{TV}(\mathrm{L})$ & $0.42 \pm 0.17$ & $0.48 \pm 0.15$ & 0.070 & - & \\
\hline FVC (\%pred) & $37.66 \pm 24.07$ & $49.55 \pm 23.82$ & $0.000^{*}$ & -0.090 & 0.604 \\
\hline FEV1 (\%pred) & $36.28 \pm 27.05$ & $48.03 \pm 28.85$ & $0.000^{*}$ & -0.206 & $0.026^{*}$ \\
\hline $\mathrm{MIP}\left(\mathrm{cmH}_{2} \mathrm{O}\right)$ & $25.51 \pm 21.97$ & $47.20 \pm 28.06$ & $0.000^{*}$ & -0.105 & 0.518 \\
\hline $\operatorname{MEP}\left(\mathrm{cmH}_{2} \mathrm{O}\right)$ & $22.70 \pm 22.99$ & $37.66 \pm 29.55$ & $0.016^{*}$ & 0.136 & 0.364 \\
\hline PCF (L/min) & $110.00 \pm 102.25$ & $205.37 \pm 115.67$ & $0.000^{*}$ & -0.110 & 0.503 \\
\hline
\end{tabular}

Values are presented as mean \pm standard deviation or number (\%).

ASIA, American Spinal Injury Association; \%pred, percentage of predicted normal; TV, tidal volume; FVC, forced vital capacity; FEV1, forced expiratory volume in one second; MIP, maximal inspiratory pressure; MEP, maximal expiratory pressure; PCF, peak cough flow.

${ }^{*} \mathrm{p}<0.05$.

Several previous studies have reported risk factors for dysphagia in individuals with CSCI, including advanced age, tracheostomy, anterior cervical surgery, level of injury, complete SCI, ventilator use, nasogastric tube, severe paralysis, and voice quality [23]. In this study, individuals with clinical features, such as a history of tracheostomy, anterior surgical approach, and higher neurological level of injury, had significantly more PA or pharyngeal residue, and these results are consistent with the findings of several previous studies [1-4,23].

Breathing and swallowing are linked physiologically and anatomically by sharing neural control centers and anatomic structures, such as the mouth, pharynx, and larynx [15]. Branches of the spinal nerves originating from the upper cervical spinal cord not only innervate the respiratory muscles but also the neck muscles, contributing to swallowing. This indirectly provides the possibility of inferring the swallowing function from the respiratory function. For example, the C1-C2 components of the upper cervical spinal nerve innervate the styloglossus, hyoglossus, genioglossus, and intrinsic tongue muscles together with the hypoglossal nerve. These groups of muscles are involved in swallowing by contributing to tongue movement [24]. Moreover, the C2-C3 components innervate the omohyoid, sternothyroid, and sternohyoid muscles. This group of muscles also contributes to the 


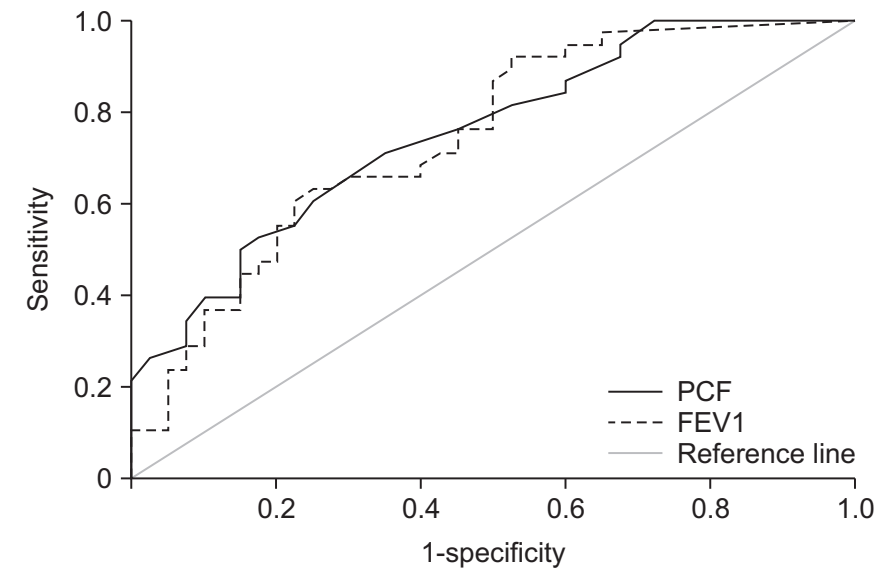

Fig. 1. Receiver operating characteristic curve analysis of peak cough flow (PCF) and forced expiratory volume in 1 second (FEV1) in the presence of penetration-aspiration.

protection of the trachea [25].

In clinical practice, pulmonary function is routinely evaluated especially in individuals with high CSCI [26]. However, the assessment of dysphagia in individuals with CSCI is often underappreciated and delayed until serious complications, including aspiration pneumonia, have occurred $[9,10,27]$. Therefore, we checked whether pulmonary function parameters, which are routinely evaluated in individuals with CSCI, could be indirect predictive factors for dysphagia. As a result of this study, we observed that the respiratory and swallowing functions were correlated in CSCI; in particular, PCF and FEV1 were related to dysphagia. Furthermore, we reported the cutoff values for PCF and FEV1 to be $140 \mathrm{~L} / \mathrm{min}$ and $37.5 \%$ of the predicted value, respectively.

Previous studies have demonstrated that voluntary cough is related to the swallowing function in various neurological diseases among the pulmonary functions. Widdicombe et al. [28] reported that voluntary coughing was mostly associated with tracheal aspiration after stroke. Smith et al. [29] demonstrated that individuals with stroke who experienced aspiration had significantly impaired voluntary cough. Pitts et al. [30] demonstrated that decreased ability of voluntary cough might aggravate symptoms resulting from penetration and aspiration, particularly in those with Parkinson disease. Plowman et al. [31] reported that voluntary cough airflow measures identified individuals with amyotrophic lateral sclerosis at risk for penetration or aspiration and might be a significant screening tool with high clinical utility. Consistent with the above studies in other neurological diseases, our study in individuals with CSCI also showed that PCF, which represents voluntary cough function, was the most powerful risk factor for predicting dysphagia among several other pulmonary function parameters.

The above results seem to arise from the following physiological reasons. Cough and swallow pattern generators are strongly coordinated and affect each other closely because they share afferent and efferent pathways $[19,32]$. Particularly, the loss of phrenic nerve function due to CSCI above C5 interrupts normal ventilation patterns and paralyzes the diaphragm with a lack of cough, disturbing airway clearance [33].

Further, FEV1 was identified to be a strong factor affecting dysphagia in individuals with CSCI. Decreased FEV1 in CSCI with dysphagia may have been caused by the affected neurological control of pulmonary function and decreased lung volume excursions due to decreased chest wall movement caused by weakness of abdominal muscles and the rib cage. Park et al. [34] demonstrated that expiratory muscle strength training was effective in dysphagia after stroke by stimulating the activity of the suprahyoid muscles, which facilitate airway protection and normal swallowing. Therefore, it is likely that FEV1, which is a major parameter of expiratory function, may indirectly suggest dysphagia.

Our results suggest that PCF and FEV1, the pulmonary function parameters showing the strongest correlations with dysphagia, may be utilized as predictive factors to identify dysphagia in CSCI. In individuals with CSCI with values lower than the cutoff values of PCF and FEV1, it may be recommended to actively examine swallowing tests, such as VFSS or fiberoptic endoscopic evaluation of swallowing, to accurately confirm dysphagia.

The limitations of this study must be acknowledged. This study was a retrospective review of medical records, which had inherent limitations of small number and heterogeneity. In this process, the selective bias cannot be completely excluded. Furthermore, the sensitivity and specificity of the cutoff values were not high enough. Therefore, it will be necessary to conduct a prospective study on a larger number of CSCI individuals with dysphagia. Tracheostomy and mechanical ventilation are strong predictors of dysphagia. However, since this study did not evaluate the duration of intubation or mechanical ventilation, or the duration of the tracheostomy, the 
effect of tracheostomy on swallowing disorders was not accurately evaluated.

In conclusion, there was a significant correlation between pulmonary function and swallowing function in individuals with CSCI. PCF and FEV1 could be regarded as significant predictive factors for dysphagia after CSCI. In particular, we suggest assessing the presence of dysphagia through VFSS if the measured PCF or FEV1 values are lower than their respective cutoff values of $140 \mathrm{~L} / \mathrm{min}$ and $37.5 \%$ of the predicted value.

\section{CONFLICT OF INTEREST}

No potential conflict of interest relevant to this article was reported.

\section{ACKNOWLEDGMENTS}

This work was supported by a 2-year Research Grant of Pusan National University.

\section{AUTHOR CONTRIBUTION}

Conceptualization: Lee SJ, Ko HY. Methodology: Lee SJ, Huh SC, Ko SH. Formal analysis: Lee SJ, Ko HY. Funding acquisition: Ko HY. Project administration: Lee SJ, Huh SC, Ko SH, Min JH, Ko HY. Visualization: Lee SJ, Huh SC, Ko SH, Min JH, Ko HY. Writing - original draft: Lee SJ, Ko HY. Writing - review and editing: Lee SJ, Ko HY. Approval of final manuscript: all authors.

\section{REFERENCES}

1. Kirshblum S, Johnston MV, Brown J, O'Connor KC, Jarosz P. Predictors of dysphagia after spinal cord injury. Arch Phys Med Rehabil 1999;80:1101-5.

2. Wolf C, Meiners TH. Dysphagia in patients with acute cervical spinal cord injury. Spinal Cord 2003;41:34753.

3. Brady S, Miserendino R, Statkus D, Springer T, Hakel M, Stambolis V. Predictors to dysphagia and recovery after cervical spinal cord injury during acute rehabilitation. J Appl Res Clin Exp Ther 2004;4:1-11.

4. Abel R, Ruf S, Spahn B. Cervical spinal cord injury and deglutition disorders. Dysphagia 2004;19:87-94.

5. Chaw E, Shem K, Castillo K, Wong SL, Chang J. Dys- phagia and associated respiratory considerations in cervical spinal cord injury. Top Spinal Cord Inj Rehabil 2012;18:291-9.

6. Zakrasek EC, Nielson JL, Kosarchuk JJ, Crew JD, Ferguson AR, McKenna SL. Pulmonary outcomes following specialized respiratory management for acute cervical spinal cord injury: a retrospective analysis. Spinal Cord 2017;55:559-65.

7. DiBardino DM, Wunderink RG. Aspiration pneumonia: a review of modern trends. J Crit Care 2015;30:408.

8. Shin JC, Yoo JH, Lee YS, Goo HR, Kim DH. Dysphagia in cervical spinal cord injury. Spinal Cord 2011;49:1008-13.

9. Iruthayarajah J, McIntyre A, Mirkowski M, WelchWest P, Loh E, Teasell R. Risk factors for dysphagia after a spinal cord injury: a systematic review and metaanalysis. Spinal Cord 2018;56:1116-23.

10. Hayashi T, Fujiwara Y, Sakai H, Kubota K, Kawano O, Mori E, et al. The time course of dysphagia following traumatic cervical spinal cord injury: a prospective cohort study. Spinal Cord 2020;58:53-7.

11. Park JW, Sim GJ, Yang DC, Lee KH, Chang JH, Nam $\mathrm{KY}$, et al. Increased bolus volume effect on delayed pharyngeal swallowing response in post-stroke oropharyngeal dysphagia: a pilot study. Ann Rehabil Med 2016;40:1018-23.

12. Grossman RG, Frankowski RF, Burau KD, Toups EG, Crommett JW, Johnson MM, et al. Incidence and severity of acute complications after spinal cord injury. J Neurosurg Spine 2012;17(1 Suppl):119-28.

13. DeVivo MJ, Krause JS, Lammertse DP. Recent trends in mortality and causes of death among persons with spinal cord injury. Arch Phys Med Rehabil 1999;80:1411-9.

14. Ghannouchi I, Speyer R, Doma K, Cordier R, Verin E. Swallowing function and chronic respiratory diseases: systematic review. Respir Med 2016;117:54-64.

15. Matsuo K, Palmer JB. Coordination of mastication, swallowing and breathing. Jpn Dent Sci Rev 2009;45:31-40.

16. Klahn MS, Perlman AL. Temporal and durational patterns associating respiration and swallowing. Dysphagia 1999;14:131-8.

17. Martin-Harris B, Brodsky MB, Michel Y, Ford CL, Walters $\mathrm{B}$, Heffner J. Breathing and swallowing dynamics 
across the adult lifespan. Arch Otolaryngol Head Neck Surg 2005;131:762-70.

18. Min SW, Oh SH, Kim GC, Sim YJ, Kim DK, Jeong HJ. Clinical importance of peak cough flow in dysphagia evaluation of patients diagnosed with ischemic stroke. Ann Rehabil Med 2018;42:798-803.

19. Lee SJ, Lee KW, Kim SB, Lee JH, Park MK. Voluntary cough and swallowing function characteristics of acute stroke patients based on lesion type. Arch Phys Med Rehabil 2015;96:1866-72.

20. Palmer JB, Kuhlemeier KV, Tippett DC, Lynch C. A protocol for the videofluorographic swallowing study. Dysphagia 1993;8:209-14.

21. Rosenbek JC, Robbins JA, Roecker EB, Coyle JL, Wood JL. A penetration-aspiration scale. Dysphagia 1996;11:93-8.

22. Han TR, Paik NJ, Park JW. Quantifying swallowing function after stroke: a functional dysphagia scale based on videofluoroscopic studies. Arch Phys Med Rehabil 2001;82:677-82.

23. Cosortium for Spinal Cord Medicine. Respiratory management following spinal cord injury: a clinical practice guideline for health-care professionals. J Spinal Cord Med 2005;28:259-93.

24. Gassert RB, Pearson WG Jr. Evaluating muscles underlying tongue base retraction in deglutition using muscular functional magnetic resonance imaging (mfMRI). Magn Reson Imaging 2016;34:204-8.

25. Nguyen JD, Duong H. Anatomy, head and neck, sternohyoid muscle [Internet]. Treasure Island, FL: StatPearls; 2021 [cited 2021 Nov 25]. Available from: https://www.ncbi.nlm.nih.gov/books/NBK547693/.
26. Berlowitz DJ, Wadsworth B, Ross J. Respiratory problems and management in people with spinal cord injury. Breathe (Sheff) 2016;12:328-40.

27. Shem K, Castillo K, Wong S, Chang J. Dysphagia in individuals with tetraplegia: incidence and risk factors. J Spinal Cord Med 2011;34:85-92.

28. Widdicombe JG, Addington WR, Fontana GA, Stephens RE. Voluntary and reflex cough and the expiration reflex; implications for aspiration after stroke. Pulm Pharmacol Ther 2011;24:312-7.

29. Smith Hammond CA, Goldstein LB, Zajac DJ, Gray L, Davenport PW, Bolser DC. Assessment of aspiration risk in stroke patients with quantification of voluntary cough. Neurology 2001;56:502-6.

30. Pitts T, Bolser D, Rosenbek J, Troche M, Sapienza C. Voluntary cough production and swallow dysfunction in Parkinson's disease. Dysphagia 2008;23:297-301.

31. Plowman EK, Watts SA, Robison R, Tabor L, Dion C, Gaziano J, et al. Voluntary cough airflow differentiates safe versus unsafe swallowing in amyotrophic lateral sclerosis. Dysphagia 2016;31:383-90.

32. Kimura Y, Takahashi M, Wada F, Hachisuka K. Differences in the peak cough flow among stroke patients with and without dysphagia. J UOEH 2013;35:9-16.

33. Hadjikoutis S, Pickersgill TP, Dawson K, Wiles CM. Abnormal patterns of breathing during swallowing in neurological disorders. Brain 2000;123(Pt 9):1863-73.

34. Park JS, Oh DH, Chang MY, Kim KM. Effects of expiratory muscle strength training on oropharyngeal dysphagia in subacute stroke patients: a randomised controlled trial. J Oral Rehabil 2016;43:364-72. 